\title{
“HACER VIVIR, DEJAR MORIR" EN LA ERA DE LA GUBERNAMENTALIDAD. ACERCA DE LA ACTUALIDAD Y DE LOS ALCANCES DEL ENFOQUE FOUCAULTIANO DE LA BIOPOLÍTICA
}

\author{
Cristina López \\ Universidad Nacional de San Martín (Unsam) \\ y Universidad del Salvador (Usal) \\ c-lopez@live.com.ar
}

\begin{abstract}
Resumen / Abstract
Las investigaciones sobre biopolítica llevadas a cabo por M. Foucault fueron objeto de una amplia recepción entre autores consagrados. Pero, a pesar de tomarlas como punto de partida para sus propios análisis, no se privaron de dirigirle críticas tan severas que obligan a preguntarse cuál es el mérito del abordaje del pensador francés. En este artículo, intentaré refutar esas objeciones y demostrar que su aporte consistió en asociar la conformación del dispositivo con el advenimiento de las gubernamentalidades liberal y neoliberal, mostrando de esta manera la incidencia sobre la vida y la muerte que ejercen ambos marcos de racionalidad política.
\end{abstract}

PALABRAS ClAVE: biopolítica, soberanía, gubernamentalidad, vida-muerte.

\section{“MAKE LIVE, LET DIE" IN THE AGE OF GOVERNMENTALITY. ABOUT THE ACTUALITY AND IMPORTANCE OF THE FOUCAULDIAN APPROACH OF BIOPOLITICS}

Foucault's researches on biopolitics were object of a wide receipt between well-knows authors. But, in spite of taking them as an inspiration for his own analyses, this did not prevent them from raising critiques so severe that it force to indagate which is the contribution of the approach of the French thinker. In this article, I will try to refute these objections and to prove that his contribution consisted of associating the conformation of the biopower with the appearance of the liberal and neoliberal gubernamentalities thus showing the impact on the life and the death exercised by both frames of political rationality.

KEY WORDS: Biopolitic, Sovereignty, Gubernamentality, Life-Death. 


\section{Introducción}

R⿴囗十 Según consignan diversas historias conceptuales, la noción de biopolítica fue acuñada mucho antes de que M. Foucault la empleara. En efecto, si nos atenemos a la indagación formulada por R. Esposito, la aparición del término data de principios de siglo XX y en su derrotero fue utilizado para designar sucesivamente un enfoque organicista, antropológico y naturalista del Estado y de la política.

Es evidente que el tratamiento realizado por Foucault de la biopolítica no se inscribe en ninguno de estos tres enfoques. De hecho, la intención de Esposito al trazar esta escueta historia del concepto no era asociar al pensador francés con ninguna de estas corrientes sino criticar su dificultad para resolver la ambigüedad que atraviesa al concepto desde su aparición. En rigor de verdad, el recurso a la historia conceptual es una de las operaciones teóricas de que se sirve Esposito para salir del "...punto muerto filosófico y político..." (Esposito 2006, p. 16) que, a su juicio, se habría originado en insuficiente indagación de los presupuestos de la cuestión biopolítica achacable a Foucault. No obstante, su crítica no se circunscribió a señalar esta insuficiencia sino que apuntaba a poner en consideración “...la compleja relación que él instituyó entre régimen biopolítico y poder soberano”. ( Ibíd., p. 17), la confusa inserción temporal que le asignó y su ambigua posición frente a la deriva tanatopolítica que lo atraviesa.

Pocos años antes, Agamben -quien al igual que Esposito considera que la aparición del concepto de biopolítica conllevó una transformación radical de las categorías políticas modernas- había formulado críticas similares al enfoque de Foucault. En efecto, aún reconociendo las investigaciones foucaulteanas como un antecedente de su propio abordaje, Agamben no se privó de destacar el déficit que las embarga por no haber focalizado el análisis en los campos de concentración nazi que, a su entender, son “...los lugares por excelencia de la biopolítica moderna...” (Agamben 2003, p. 13). Además, anticipándose a Esposito, Agamben le reprochó a Foucault no haber advertido la relación entre el modelo jurídico de ejercicio de poder y la biopolítica. De allí que concibiera su propia investigación como un recurso para alumbrar ese 'punto ciego' en el campo visual del pensador francés. Pero, G. Agamben no se conformó con incorporar el modelo jurídico al tratamiento de la biopolítica desdibujando las diferencias entre ambos dispositivos, sino que, vía una operación teórica consistente en, por una parte, retomar los análisis aristotélicos que dan cuenta del carácter político del vivir humano y, por otra parte, recurrir a una figura del derecho romano arcaico como la del 'Homo Sacer', hizo coincidir este interés del poder por la vida con los orígenes mismos de la política occidental. Así las cosas, más que ampliar el registro de la mirada del pensador francés, Agamben se propuso directamente corregir o al menos completar la tesis foucaulteana, en un sentido, a nuestro entender, inadmisible por Foucault, por cuanto implica suponer una suerte de continuidad y hasta de evolución histórica entre antigüedad y modernidad de modo que “... el espacio de la nuda vida que estaba situada originariamente al margen del orden jurídico, va coincidiendo de manera progresiva con el espacio político, de forma que exclusión e inclusión, externo e interno, bíos y zõê, derecho y hecho, entran en una zona de irreductible indiferenciación" (Agamben 2003, p. 19). 
Más radical aún resulta la crítica formulada por Didier Fassin, quien sostuvo que, en realidad, a Foucault "[1] as cuestiones de la vida en sí [...] no le interesan" (Fassin 2010, p. 25). A entender de Fassin, la teoría de la biopolítica que Foucault habría esbozado en 1976 nunca se habría concretado debido a su decisión de dedicarse a las cuestiones de la gubernamentalidad y de la subjetivación. Según esta lectura, al abocarse al estudio de la gubernamentalidad, el eje de la atención de Foucault se habría desplazado del problema de la vida hacia el análisis de la manera de conducir la conducta de los hombres. Como consecuencia de este desplazamiento, las investigaciones foucaulteanas sobre la biopolítica se habrían centrado en el estudio de la conducta de la población y, concomitantemente, de los procedimientos de normalización. De tal suerte que los problemas que afectan a la vida y a la muerte habrían quedado sin abordar por el pensador francés.

Ahora bien, ante una recepción tan crítica, cómo evitar preguntarnos: ¿cuál es el mérito del enfoque foucaultiano del dispositivo biopolítico? Al respecto, en lo que sigue, procuraré mostrar que, contra lo que opinan estos destacados autores, el aporte de la perspectiva de análisis de Foucault consiste precisamente en circunscribir el ejercicio positivo del poder sobre la vida al periodo comprendido entre fines del siglo XVIII y nuestros días, diferenciándolo netamente de los regímenes soberano y disciplinario y haciéndolo coincidir con la emergencia de las prácticas gubernamentales del liberalismo primero y del neoliberalismo después. Óptica desde la cual se advierte que los campos de concentración del nazismo no fueron el lugar por excelencia de la biopolítica sino un caso, sin duda paroxístico, pero que, con todo, no alcanza para encandilar la deriva mortífera que es inherente a la lógica misma del dispositivo aún vigente. Por esta vía, como intentaré poner en consideración, lejos de convertir el dispositivo en una reliquia de prolongados estertores o dejar en la indefinición su inserción temporal, M. Foucault logró poner en evidencia su radical actualidad. Al reconocer en la gubernamentalidad liberal el marco de racionalidad política en el que está incursa la biopolítica, dotó de una vigencia inaudita a sus propios análisis. Pero, más importante, al mostrar la intrínseca relación entre gubernamentalidad y biopolítica, puso en evidencia el arsenal tanático de que se valen liberalismo y neoliberalismo para hacer vivir a una parte de la población. En palabras más contundentes, advirtió que, en forma estrepitosa o sigilosamente, el liberalismo y el neoliberalismo matan.

\section{De la soberanía como derecho de hacer morir y dejar vivir}

En sus primeros abordajes más sistemáticos de la cuestión biopolítica ${ }^{1}$, Foucault acuñó dos fórmulas que mostraron las diferencias insalvables que, a su juicio, distinguían a

Sin desconocer que ya en conferencias como "La naissance de la médicine sociale" dictadas en 1974 en la Universidad Estadual de Río de Janeiro, Foucault se había referido a la biopolítica, considero que recién hizo un análisis más sistemático de la cuestión a partir 
la soberanía de la biopolítica. En efecto, el pensador francés refirió el accionar propio de la soberanía con la expresión 'derecho de hacer morir y dejar vivir', mientras que para caracterizar el ejercicio biopolítico del poder recurrió a la fórmula 'hacer vivir y dejar morir'.

Tomada al pie de la letra, la primera expresión permite colegir que, para Foucault, la soberanía es un poder que se ejerce de forma asimétrica, privilegiando la muerte en detrimento de la vida. Es que la soberanía se manifiesta en todo su esplendor cuando arrebata la vida. De allí que 'haga morir' en el transcurso de una ceremonia pública y bajo una forma eminentemente atroz como el suplicio. Dejar vivir es solo una prerrogativa de la que hace uso en circunstancias excepcionales sin que ello afecte la magnificencia de su poder. Dicho de otra manera, su interés se centra en hacer efectivo su derecho a hacer morir y, si deja vivir es, en todo caso, como efecto colateral de su poder mortífero. En términos de Foucault, "[e]1 soberano no ejerce su derecho sobre la vida sino haciendo valer su derecho de matar, o reteniéndolo; no deja constancia de su poder sobre la vida sino por la muerte que está en condiciones de exigir" (Foucault 1976, p. 178). En suma, a diferencia de la biopolítica que -como veremos- se afinca en la vida, la soberanía se aplica “...del lado de la muerte” (Foucault 1997, p. 214).

No es ésta la única ni la más relevante diferencia entre ambos dispositivos. Basta con reparar en la totalidad de la fórmula destinada a explicitar la operatoria propia de la soberanía para advertir que, entre soberanía y biopolítica, hay diferencias de herramientas de ejercicio del poder e incluso de objeto al que se aplican una y otra. En cuanto a las herramientas, la fórmula destaca el rol que cumple el derecho al servicio de la soberanía. Rol complejo por cuanto, a la vez que legitima la potestad del soberano, la delimita y, por esta vía, termina por interponerse entre éste y la vida y la muerte de sus súbditos. En este sentido, por poderoso que se considere el soberano, no puede hacer uso de este derecho en forma absoluta e incondicional sino solo cuando su existencia misma se vea amenazada o en ocasión de una guerra. Es entonces y por la interposición de la voluntad del soberano que la vida y la muerte de los súbditos se tornan jurídicamente disponibles. De manera que, al ejercerse a través de la mediación del derecho, la soberanía no se aplica directamente sobre la vida o la muerte en tanto “...fenómenos naturales, inmediatos, de alguna manera originarios o radicales, que caerían fuera del campo del poder político" (Foucault 1997, p. 214) sino en tanto jurídicamente cualificados.

De donde se infiere que, a pesar de las apariencias, la soberanía no se aplica sobre el mismo objeto que la biopolítica. De hecho, tal como especifica la cita, la soberanía no se ejerce sobre la vida y la muerte biológicamente consideradas sino sobre el 'derecho de vida y de muerte'. Salta a la vista que las diferencias entre soberanía y biopolítica no se reducen a una mera contraposición entre dos dispositivos que, en el límite a fuer de

de 1976, tanto en la última clase del curso dictado en 1976 como en el último capítulo de Histoire de la sexualité 1. 
antagónicos, podrían devenir complementarios. No hay relación de complementación entre dispositivos que se ejercen sobre distintos objetos a través de distintos medios.

Así las cosas, resulta evidente que ya en aquellas primeras presentaciones de la biopolítica, Foucault se esmeró en exponer las diferencias que la torna irreductible a la soberanía. Con todo, justo es reconocer que, a la par que se expedía con tanta nitidez, intercaló algunas formulaciones sumamente ambiguas como aquellas en las cuales la biopolítica es caracterizada como un derecho que vendría a completar la soberanía.

Esta ambigüedad respecto de la relación y alternancia entre soberanía, disciplina y biopolítica persistió hasta promediar el curso de 1978 en donde el propio Foucault reconoció que "[e]n apariencia, si quieren, les he dado una especie de esquema histórico totalmente descarnado" (Foucault 2004, p. 8). No obstante, en lo inmediato no pareció encontrar una vía adecuada para rellenar el vacío de ese esquema. Por el contrario, al menos en la primera clase y aun admitiendo la necesidad de hacer una historia de las técnicas y una historia de las tecnologías, ensayó una respuesta igualmente ahistórica al señalar que los dispositivos no se suceden los unos a los otros sino que más bien hay una "...serie de edificios complejos en los cuales lo que va a cambiar, por supuesto, son las técnicas mismas que van a perfeccionarse, o en todo caso complicarse, pero sobre todo lo que va a cambiar, es la dominante o más exactamente el sistema de correlación entre los mecanismos jurídico-legales, los mecanismos disciplinarios y los mecanismos de seguridad" ( Ibíd. p. 10). Explicación que no se compadece con los ejemplos que el propio autor eligió para mostrar las diferencias irreductibles entre los dispositivos. De hecho, de sus propias descripciones se desprende que cada dispositivo ha desplegado sus propias e incomparables formas de reaccionar frente al delito, al tratamiento del espacio urbano, al abordaje de lo aleatorio, etc. En todos los casos reseñados, el contraste entre las técnicas empleadas por cada dispositivo hace inviable la postulación de un sistema de correlación.

No fue sino hasta desembocar en el tratamiento de la aparición histórica del problema político de la población y del descubrimiento de una tecnología política afín al manejo de este problema que el pensador francés pudo empezar a circunscribir histórico políticamente la conformación del dispositivo biopolítico. Como sabemos, el descubrimiento de la tecnología de gobierno provocó en Foucault una reformulación de su grilla de análisis de las relaciones de poder. Ya en Histoire de la sexualité 1, había advertido la necesidad de producir un cambio de óptica que implicara optar por "el modelo estratégico y no el modelo del derecho. Y ello no por opción especulativa o preferencia teórica, sino porque uno de los rasgos fundamentales de las sociedades occidentales consiste, en efecto, en que las relaciones de fuerza -que durante mucho tiempo habían encontrado en la guerra, en todas las formas de guerra, su expresión principal- se habilitaron poco a poco en el orden del poder político" (Foucault 1976, p. 135). En el contexto del curso de 1978, el pensador francés llegó a percibir la intrínseca relación entre la emergencia de la población y la conformación del gobierno como consecuencia de la anunciada indagación de la historia de las tecnologías de poder. En otras palabras, el esquema comenzó a adquirir carnadura cuando, además de contraponer las prácticas aplicadas por cada dispositivo, Foucault estableció los mojones de la inserción histórica de las tecnologías de poder. Estos mojones le permitieron modificar la periodización 
y la modalidad establecidas en el curso de 1976. En efecto, en aquel momento, había homologado la biopolítica al fenómeno fundamental del siglo XIX consistente en una estatización de lo biológico. La indagación histórica del curso de 1978 lo condujo a emplazar la aparición de la biopolítica en el siglo XVIII en coincidencia con la emergencia conjunta de la población y de una modalidad de gobierno más vinculada a la racionalidad económica que a la figura del Estado. De allí que Foucault dedicara gran parte de este curso inicialmente destinado al tratamiento del bio-poder ${ }^{2}$ a trazar una historia conceptual y genealógica de la gubernamentalidad.

De manera que, aun cuando hubo que esperar hasta el curso de 1979 para que Foucault se expidiera contundentemente respecto del marco de racionalidad política en el que se inscribe la biopolítica, ya en Seguridad, Territorio, Población tenía clara noción de su vinculación con las tecnologías puestas en práctica por los gobiernos de matriz economicista. Por donde se advierte que, contrariamente a lo que sostiene Didier Fassin, en modo alguno el interés de nuestro pensador por la gubernamentalidad implicó un viraje que lo alejó definitivamente de su preocupación por las cuestiones de la vida y de la muerte. Lejos de ello, como intentaremos explicitar más adelante, el estudio de la gubernamentalidad constituye un capítulo indispensable de la concepción foucaulteana de la biopolítica.

\section{De la biopolítica como poder de hacer vivir}

No obstante, para comprender la especificidad e irreductibilidad de la concepción de la biopolítica de Foucault es menester empezar por analizar la fórmula que acuñó para designar su modalidad propia de ejercicio del poder. Según reza esa fórmula, el dispositivo se caracteriza por 'hacer vivir y dejar morir'. Basta con transcribirla para advertir que, para el pensador francés, la biopolítica vino a invertir término a término la modalidad soberana. Efectivamente, en contexto biopolítico, ya no se trata de hacer uso del derecho a hacer morir o exceptuar de esa condena sino de propugnar la vida al punto de, al menos en apariencias, dejar morir cuando ya no haya otra alternativa. En lo inmediato, cabe registrar el cambio de signo que torna incompatibles ambos dispositivos, puesto que mientras que la soberanía se cobraba toda acechanza a la integridad del soberano con la negación vía la destrucción o la exposición de la vida a la muerte, sin que se presente ninguna circunstancia excepcional, la biopolítica se ejerce positivamente haciendo vivir. A diferencia, entonces, de la soberanía, la biopolítica no necesita ninguna excusa para ejercerse continuamente $y$, al parecer, predominantemente del lado de la vida. 'Positivamente', entonces, designa un ejercicio afirmativo que hace consistir la vida en lugar de anonadarla. Ello no implica que se trate de un poder inocuo o menos virulento que otros. Por el contrario, logra incidir sobre aquello que los otros dispositivos no osaban tocar. Precisamente, es en virtud de su carácter 'positivo' que 
consigue ser tan eficaz para dar entidad y moldear la vida a su antojo. En otros términos, la vida no existía hasta que un determinado régimen de poder/saber empleando una serie de prácticas específicas la hizo consistir como objeto epistemológico y como objeto de interés político. En este sentido, este dispositivo -como los anteriormente analizados por nuestro autor- se comporta como una cantera ontológica de la que, en este caso, emerge la vida como entidad de referencia. Por donde se advierte que la analítica del poder, tal como lo reconoció en más de una oportunidad el propio Foucault ${ }^{3}$, conllevaba siempre una ontología histórica. Según esto, los dispositivos se diferencian también por los sujetos/objetos que producen. De hecho, mientras la soberanía da lugar a un sujeto jurídico cuyo cuerpo puede ser sometido a suplicio, expandida por toda la sociedad, la disciplina contribuye a conformar un sujeto potenciado físicamente y depotenciado políticamente, esto es, resistente y productivo pero obediente hasta la sumisión, y la biopolítica dota de consistencia política y epistemológica a la vida.

No son estas las únicas divergencias que nuestro autor puntualiza entre ambos dispositivos. De hecho, como vimos, la soberanía se basaba en un régimen jurídico siendo el derecho su herramienta de ejercicio y, en cierta medida, también su objetivo, en tanto que la biopolítica no requiere ni recurre al derecho para ejercerse: arremete sin interposición alguna sobre la vida misma. En ese sentido, son la vida y la muerte en tanto fenómenos naturales y ya no como 'derechos' los que están en su mira. En esta exposición directa de la vida y de la muerte al poder reside la novedad de la biopolítica. En rigor de verdad, la biopolítica como cualquier dispositivo hace uso de una serie de tecnologías de saber/poder para cumplir su cometido. Pero, a diferencia del derecho que cumplía el doble rol de herramienta del soberano y amparo de la vida y de la muerte de sus súbditos, estas tecnologías actúan sobre una vida desprovista de toda protección.

De entre las tecnologías propiamente biopolíticas, en sus textos y cursos Foucault destacó disciplinas como la medicina de la que llegó a sostener que “...va a ser una técnica política de intervención, con los efectos de poder propios" (Foucault 1997, p. 225). Ninguna otra disciplina parece más adecuada que la medicina para trajinar con los vericuetos que afectan a la vida como la natalidad, la enfermedad, la morbilidad, la longevidad, fenómenos todos que atañen a la población. También resaltó el rol que desempeñan la economía política, la biología y hasta la filología en relación con la aparición de ese nuevo objeto de preocupación política que es la población. De allí la escala a la que se mueve la biopolítica que, a diferencia de la disciplina, no repara en

3 Cfr. Foucault, M., Surveiller et Punir. Naissance de la prison, Paris, Gallimard, 1975, pp. 27-35 en donde nuestro autor a propósito del objetivo del texto sostiene que se trata de trazar en forma conjunta "une histoire correlative de l'âme moderne et d'un pouvoir de juger..." y "Pourquoi étudier le pouvoir : la question du sujet" en Dreyfus, H. y Rabinow, P., Michel Foucault: Beyond Structuralism and Hermeneutics, Chicago, The University of Chicago Press, 1982. Ahora en Dits et écrits, Vol. IV, Paris, Gallimard, 1994, pp. 222-232 ; en donde para sorpresa de muchos sostuvo que el interés que había guiado su trabajo no era analizar los fenómenos de poder sino producir una historia de los diferentes modos de subjetivación del ser humano en nuestra cultura. 
los cuerpos de los individuos sino en la vida de la especie humana organizada como población. En otros términos, mientras que para cumplir con su objetivo la disciplina precisaba someter a los cuerpos a un proceso de individualización y de exhaución de sus capacidades, a través de sus tecnologías, la biopolítica va por más: se atreve a lidiar con la vida misma no de tal o cual individuo sino de la especie. Precisamente, a través de la intervención sobre la vida de la especie, la biopolítica pretende gestionar a esa masa anónima en constante movimiento que es la población.

Pero, ¿cómo logra dar cumplimiento a semejante pretensión el dispositivo? En otras palabras, ¿cómo hace vivir la biopolítica? ¿Cómo se las ingenia para llegar a abarcar una totalidad tan amplia y diversa como la que constituye una población? Precisamente para poder responder a estas preguntas, Foucault se vio obligado a trazar una genealogía del gobierno. En rigor de verdad, como fue dicho anteriormente en este artículo, el interés por el gobierno tuvo distintas motivaciones e importantes implicancias en el pensamiento de nuestro autor. Sus manifestaciones al inicio del curso del 76 daban cuenta de su disconformidad con la grilla belicosa de análisis de las relaciones de poder que venía empleando, seguramente porque ya había advertido que no se aplicaba al análisis del modelo estratégico de poder ejercido en las sociedades modernas. De allí su necesidad de elaborar una perspectiva más adecuada para estudiar el funcionamiento de estas sociedades que tienen como objeto político la vida de la población. Así, aunque no incluyó la especificación de esta cuestión entre las precisiones metodológicas que formuló al inicio del curso del 78, promediando la tercera clase, quedó claro que para dar cuenta de los dispositivos securitarios tenía que adoptar otro criterio de enfoque. La referencia a esta tecnología no belicosa sino política de ejercicio del poder marca un punto de inflexión no solo en el proceso de elaboración de una grilla de análisis diferente sino también en la orientación de las investigaciones sobre biopolítica que, a partir de allí, dio relevancia al tratamiento de la gubernamentalidad.

Así las cosas, a nuestro juicio, la exploración del gobierno y de la población no puede ser vista como una deriva motivada por el desinterés de Foucault en los asuntos de la vida y la muerte. Por el contrario, si efectivamente estaba concernido por estas cuestiones no podía evitar indagar las características de esta modalidad de ejercicio de poder y su objeto. Incluso el rumbo que le dio a su genealogía que lo llevó a revisar el poder pastoral se justifica en la medida en que constituyó la base para identificar la acción propia del gobierno como 'conducción de la conducta'.

A juzgar por los análisis de Foucault, la eficacia del dispositivo reside en intentar pasar prácticamente desapercibido. Al menos así surge del contrapunto entre dispositivos con el que nuestro autor inició su curso de 1978, en donde puede apreciarse que, a diferencia del ensañamiento que caracteriza tanto a la soberanía como a la disciplina, la biopolítica parece respetar y orientarse por el orden natural de las cosas e incluso dejar en libertad de acción, más aún, promover la libertad de la población. Basta recordar que uno de los principios liberales más conocidos insta a "dejar hacer, dejar pasar", dando a entender que la actitud más apropiada del gobierno es la prescindencia frente la población cuya naturaleza sería inútil querer modificar por ley. No obstante, a despecho de lo que los gobiernos de matriz economicista pretenden sostener, su presunta abstención constituye una intervención política que se inscribe e incide en la vida de la 
población. En términos de Foucault, “....esta ideología de libertad, esta reivindicación de libertad ha sido una de las condiciones del desarrollo de las formas modernas o, si ustedes quieren, capitalistas de la economía" (Foucault 2004, p. 49). De manera que, el 'dejar hacer, dejar pasar' solo es expresión de un cierto tipo de libertad en un determinado contexto. Respecto del contexto, en la medida en que refiere al desarrollo de unas formas tildadas como 'modernas' y 'capitalistas' de la economía, la cita deja en claro que no fue en función de respetar el natural desenvolvimiento de la realidad ni en pos de la promoción de la libertad que el liberalismo alentó el 'dejar hacer, dejar pasar'. Por el contrario, había que dejar hacer y dejar pasar para incidir en la realidad impulsando el desarrollo del capitalismo. En este sentido, más que como apelación a la libertad, el principio funcionó como una tecnología de poder consistente en promover la libre circulación de la población y las mercancías con el objetivo de favorecer las aspiraciones del dispositivo. De allí que Foucault culminara la segunda clase del curso de 1978, señalando que más que como ideología, hay que comprender al liberalismo como una tecnología de poder que se concibe a sí misma como operando a través de regulaciones entre las cuales se cuenta en primerísimo lugar el aprovechamiento de la libertad de la población.

Ahora bien, ¿qué tipo de prácticas conforman principios como el referido? ¿Cómo logran intervenir sobre la presunta naturaleza de su objeto? ¿Qué objetivos persiguen? ¿Qué implicancias para la vida conlleva el cumplimiento de estos objetivos? De lo expuesto por nuestro autor en sus cursos, sobre todo en el de 1978, surge que los principios liberales dan lugar a normas, medidas, regulaciones que tienen la habilidad tanto de penetrar la naturaleza de la vida de la población como de actuar 'a distancia', es decir, sin aplicarse directamente sobre la población pero produciendo igualmente los efectos ansiados. Ocurre que en este marco se considera que la población está conformada por una doble naturaleza, una de carácter físico que la vuelve permeable a la incidencia de una serie de variables como el medio, el clima, la prosperidad o la carestía; otra de carácter conductual, cuyo núcleo es el deseo igualmente permeable a las técnicas de poder, toda vez que éstas tengan la astucia de dejarlo oscilar en ciertos límites hasta lograr enfocarlo hacia la apetencia de lo que, en cada caso, se considera el interés general. En cuanto a la naturaleza física de la población es también objeto de una regulación a distancia como cuando se toman decisiones que afectan el medio ambiente o incluso se adoptan medidas que propenden a estimular la natalidad. En todo caso, el objetivo a alcanzar no es la obediencia ni el disciplinamiento, sino la normalización de la población. Por normalización no hay que entender aquí el sometimiento a una norma sino la homogeneización de la población en torno a una media general establecida por la vía del análisis y la estadística. De allí la importancia en contexto biopolítico de estos recursos metodológicos que permiten identificar los criterios para gestionar a la población, esto es, adecuar su rendimiento, sus consumos, sus expectativas. El objetivo no es la beneficencia ni el bienestar general sino la obtención de un rédito que no parezca resultado de una intromisión violenta sino que cuente incluso con la aquiescencia de la propia población. El neoliberalismo ha mostrado un talento destacable a este respecto. Prueba de ello son categorías como la de 'capital humano', con la cual se refiere a esa doble naturaleza de la población distinguiendo los elementos innatos y los elementos 
adquiridos. En una inédita expansión de la injerencia de la economía en ámbitos ajenos a su incumbencia y antes de tomar cualquier decisión al respecto, los gobiernos neoliberales ponderan la relación costo/beneficio de una intervención en alguno de los dos órdenes. Así, ni las intervenciones genéticas en procura de mejorar los elementos innatos ni las ampliaciones de las licencias por maternidad que intentan incidir en la estabilidad física y emocional de la madre y el niño se realizan espontáneamente o por criterios humanitarios: hay un capital en juego y es menester saber operar sobre él de modo de obtener los beneficios deseados. En nuestros días, como bien puntualiza Luca Paltrinieri (2013), hemos sido instados a colaborar en el intento de incrementar este capital a través de procesos de formación continua que ofrecen las empresas para mejorar este capital a través de la formación continua. Y, convencidos de nuestro rol proactivo como emprendedores empresarios de nosotros mismos, nos hemos aplicado a perfeccionar, actualizar, especializar nuestras competencias.

No obstante, la astucia del dispositivo ha sido tan efectiva que ha llevado tiempo advertir sus estrategias y oponerles resistencia. En efecto, no parece fácil resistirse a una modalidad positiva de ejercicio del poder que en todo momento parece propender a optimizar la vida. Se trata, como es evidente, de un problema político que excede las insuficiencias que se le puedan adjudicar al enfoque de Michel Foucault. No obstante, es uno de los aspectos que más se le ha criticado en general y particularmente en relación con sus indagaciones de biopolítica. En líneas generales, se lo ha acusado de ser parasitario de aquello mismo que crítica y de no ofrecer una alternativa de recambio. En referencia a los cursos sobre biopolítica, mucho se ha debatido sobre los alcances de las consideraciones de nuestro pensador sobre el suicidio como expresión de una voluntad singular de resistencia al mandato biopolítico de vivir. Sin desconocer estas y otras apreciaciones sobre la muerte ni pretender abrir un flanco como el del abordaje sobre la resistencia que exigiría un tratamiento en profundidad, me permito suscribir aquellas precisiones según las cuales "[y] contra este poder aún nuevo en el siglo XIX, las fuerzas que resisten se apoyaron sobre aquello mismo que aquel investía -es decir sobre la vida y el hombre en tanto que viviente" (Foucault 1976, p. 190). No se trata de una opción arbitraria: como lo remarca el propio Foucault, “...se tiene aquí un proceso muy real de lucha..." ( Ibíd., p. 191), a mi entender, mucho más productiva políticamente que la opción por la muerte. En términos del autor, “...la vida como objeto político ha sido de alguna manera tomada al pie de la letra y vuelta contra el sistema que pretendía controlarla" (Ibíd). De modo que si, como señalan algunos comentaristas ${ }^{4}$, hay una biopolítica afirmativa en Foucault, entendiendo por tal aquella que se ejerce en nombre de la vida y no sobre ella, habría que empezar a rastrearla en estas precisiones. En todo caso, no es del lado de la muerte que se libra la batalla contra la biopolítica. Por el contrario, como esperamos mostrar en el próximo apartado, del lado de la muerte, ya sea sigilosa o estrepitosamente, la biopolítica ejerce su poder tanático.

4 Entre ellos, cabe remarcar los análisis formulados por Judith Revel en su curso sobre "Arqueología, genealogía, actitud. Foucault, la historia y la 'diferencia posible"”, dictado en octubre de 2012 en la UNSAM. 


\section{De la biopolítica como poder de 'dejar morir'}

El lado de la muerte y el poder tanático adjudicado por Foucault a la biopolítica han sido tópicos escasamente abordados por comentaristas y críticos. Probablemente esta omisión obedezca a la expresión acuñada por el pensador para dar cuenta del modo en que el dispositivo se ocupa de la muerte. En efecto, la expresión 'dejar morir' es lo suficientemente ambigua como para sugerir la presunta indiferencia de esta modalidad de ejercicio del poder frente a la muerte y, por ende, no ameritar un tratamiento específico. No obstante, Foucault le dedicó a la cuestión un lugar relevante. De hecho, promediando la última clase del curso de 1976, identificó la concepción de muerte sobre la que se aplica el dispositivo. De acuerdo con sus análisis, a diferencia de la concepción medieval según la cual la muerte irrumpe súbitamente en la vida, en contexto biopolítico y, en buena medida, como resultado de los hallazgos de patólogos como X. Bichat, la muerte se concibe como una amenaza permanente. Ocurre que, en el medioevo, las epidemias tornaban inminente y repentina la muerte para todos los hombres. En términos de Foucault, se trataba de "...la muerte que se abate brutalmente sobre la vida" (Foucault 1997, p. 217). A fines del siglo XVIII, en cambio, el fenómeno es otro: ya no es cuestión de epidemias sino de endemias, esto es, de las enfermedades que afectan en forma constante y natural a la población disminuyendo sus fuerzas, alterando su rendimiento, afectando sus potencialidades. Y aunque no siempre provocan la muerte, son un índice cierto de su presencia continua. De modo que, en contexto biopolítico, la muerte no llega al final de la vida tomándola desde fuera sino que "...se desliza en la vida, la roe permanentemente, la disminuye y la debilita" (Ibíd). La presencia amenazante de la muerte es tal que Bichat definió a la vida como el conjunto de funciones que resisten a la muerte. Frente a esta amenaza, la biopolítica parece impotente. Aún en nuestros días y a pesar de todos los avances científicos tecnológicos, el dispositivo no puede evitar que la muerte haga su trabajo cotidiano. De allí que, al no poder administrarla a su antojo, la descalifica. Al menos esta es una de las primeras declinaciones que el propio Foucault le asigna a la expresión 'dejar morir'. A su entender, la desaparición de los rituales y ceremonias fúnebres que antaño daban visibilidad a la muerte no se explica por un cambio espontáneo de sensibilidad. Hay que entenderla en el marco de un dispositivo que, consagrado a hacer vivir, no puede sino sentirse desafiado por una muerte que le hurta de las manos su presa y, por ende, en lugar de promover su ritualización pública, opta por ocultarla. Es que, en cierto sentido, la muerte representa “...el momento en que el individuo escapa a todo poder, cae sobre sí mimo y se repliega, de alguna manera, sobre su ámbito más privado" ( Ibíd., p. 221). Así las cosas, la muerte podría ser vista como el límite, el punto de fuga del poder. Si así fuera, y el ejemplo de la muerte de Franco que nuestro autor evocó parece corroborarlo, al dispositivo no le queda más que ignorar la muerte y, por lo tanto, 'dejarla caer' o resignarse a 'dejar morir'.

Ahora bien, el ejemplo de la muerte de Franco en sí mismo es lo suficientemente ambiguo como para extraer una conclusión diferente. En efecto, cuando se analizan las circunstancias que rodearon esa agonía, se advierte que la medicina se las ingenió para mantener con vida al dictador hasta que estuviera resuelto el problema político de la sucesión. En ese sentido, más que claudicar ante la muerte, el dispositivo probó 
ser lo suficientemente eficaz como para 'dejar morir' en el momento adecuado. Es cierto que hay circunstancias como las del suicidio, en las que la vida del individuo parece sustraerse al poder. Pero, resulta difícil asignarle a un acto tan personal con motivaciones tan diversas un valor político aunque haya entre quienes tomen tan cruenta decisión algunos que lo hagan convencidos de liberarse por ese medio de las condiciones políticas que afligen su vida. Se trata, como puntualizó Foucault, de "...una obstinación en morir..." difícil de digerir por el dispositivo aunque ya hace tiempo que ha entrado en sus cálculos estadísticos como demostró en su momento E. Durkheim (2012). En todo caso, de estas observaciones no se sigue la indiferencia del dispositivo frente a la muerte sino más bien su preocupación. En rigor de verdad, como advirtió prontamente nuestro pensador, el proactivo 'dejar morir' es un complemento que fortalece la lógica del dispositivo ${ }^{5}$.

Efectivamente, en el marco de la última clase del curso de 1976, Foucault se mostró titubeante respecto de la justificación del accionar mortífero del dispositivo, a punto tal que intentó explicarlo como una consecuencia de la reactivación del poder soberano ${ }^{6}$. Según esta línea argumentativa, como en sus tiempos, la soberanía requiere de una causa 'legítima' para hacer morir. Causa que encuentra en la aplicación de la noción de 'raza' con la finalidad de introducir una ruptura en el 'continuum' biológico. De hecho, por la vía de su interposición, fue factible establecer una suerte de jerarquía conducente a calificar y clasificar las poblaciones de distinta procedencia. En otras palabras, el recurso a la noción de raza fue una estrategia consistente en “...fragmentar este campo biológico que el poder tomó a su cargo; una manera de separar en el interior de la población grupos los unos por relación con otros" (Foucault 1997, p. 227). De esta noción se muñó el nazismo para exterminar a aquella raza que, según sus prejuicios, amenazaba con contaminar la pureza aria. En la medida en que permite eliminar a parte de la población en salvaguarda de la otra, la excusa de la contaminación no interfiere con la lógica del dispositivo. Por el contrario, lo refuerza en tanto se trata de 'dejar morir' para 'hacer vivir' No es extraño que en aquella clase nuestro pensador haya desembocado en el tratamiento del holocausto nazi. Al fin y al cabo, se trataba de una clase destinada a explicitar la forma que adoptó la guerra de razas en el siglo $\mathrm{XX}$. Y aunque no dejó de llamar la atención sobre el paroxismo que adquirió el 'dejar morir' durante el nazismo cuando se ejecutó como un imperativo de muerte o 'mise à mort', no focalizó ni mucho menos acotó a este acontecimiento histórico su análisis de la función tanática de la biopolítica. De allí que no haya tomado a los campos de concentración como lugares por excelencia en los que se desarrolla la biopolítica como lo hizo Agamben. Ello no implica que haya desconocido la apoteosis mortífera que reinaba en los campos ni que haya subestimado la voluntad tanática de la biopolítica. Por el contrario, ya en la misma clase enfocó la cuestión como inherente al Estado moderno tanto en su versión capitalista cuanto en su versión socialista. De esta manera, contribuyó a poner en consideración una tendencia para nada excepcional sino cotidiana 
de nuestras sociedades. Es cierto que en aquella clase siguió esgrimiendo el argumento de la reactivación del poder soberano y mostrando la perversa utilidad de la categoría de raza toda vez que es cuestión de eliminar a un adversario y, ello sigue de alguna manera tributando a la idea de la excepcionalidad de la deriva tanática. En efecto, según sus análisis, los gobiernos socialistas recurren a la noción de raza en sentido evolucionista y no ya étnico cuando tiene que ejercer el derecho de matar.

No obstante, en el mismo año, en Histoire de la sexualité I, dio un giro radical a su argumentación. En sus palabras, "[s]i el genocidio es el sueño de los poderes modernos, no es por un retorno actual del viejo derecho de matar; es porque el poder se sitúa y se ejerce al nivel de la vida, de la especie, de la raza y de los fenómenos masivos de población" (Foucault 1976, p. 180). Esta afirmación obliga a reconsiderar el sentido del 'dejar morir' que, en modo alguno, puede sugerir la pasividad o indiferencia del dispositivo frente a la muerte sino que, por el contrario, refiere un modo activo de posicionarse a su respecto. Efectivamente, según se infiere de la cita, para 'dejar morir', la biopolítica no requiere recurrir a la actualización del poder soberano. Le basta con escudarse en su voluntad de 'hacer vivir'. En rigor de verdad, la cita establece con claridad que hace a la lógica del dispositivo biopolítico 'dejar morir' activa y propositivamente. No es entonces por error, omisión o exceso excepcional que la biopolítica 'deja morir': es por mor de la vida que gestiona la muerte. Foucault no lo ignora. De allí que afirme: "Esta muerte, que se fundaba sobre el derecho del soberano de defenderse o de exigir que se lo defienda, va a aparecer como el simple reverso del derecho para el cuerpo social de asegurar su vida, mantenerla o desarrollarla" (Ibíd., p. 179).

A la luz de estas afirmaciones, es lícito presumir que, entre la última clase del curso de 1976 y el texto con el que cerró el primer volumen de Histoire de la sexualité, el pensador francés había profundizado sus análisis sobre el ejercicio biopolítico del poder. Sobre todo en lo que concierne a la función mortífera. De hecho, en el texto sobre la sexualidad, sus consideraciones sobre el rol del 'dejar morir' en el dispositivo preceden al tratamiento de las variantes del 'hacer vivir'. Es que entre una y otra exposición, el pensador se convenció de que “....este formidable poder de muerte -es quizás lo que le otorgue una parte de su fuerza y del cinismo con el cual [la biopolítica] ha llevado tan lejos sus propios límites..." (Ibíd). Su reseña de las formas de ejercicio del 'dejar morir' en las sociedades contemporáneas fundamenta esta presunción. Este ejercicio contempla formas estrepitosas como las guerras sangrientas, los nuevos holocaustos, las masacres, todas ellas practicadas en nombre de la defensa y preservación de la vida de todos.

Con todo, no son éstas las únicas formas de 'dejar morir' de que dispone el dispositivo. Cuenta con un arsenal de prácticas mucho más sigilosas pero igualmente eficientes a la hora de 'arrojar a la muerte' a aquella parte de la población que no es de su interés preservar. Ni el amor ni la sexualidad quedaron al margen de los análisis de nuestro autor. De hecho, en su trabajo sobre la sexualidad sostuvo que, "[c] uando Occidente, [...] descubrió el amor, le acordó suficiente valor como para hacer aceptable la muerte" (Foucault 1976, p. 206). A su entender, incurso en la biopolítica, el dispositivo de sexualidad “...inscribió en nosotros la tentación [...]: intercambiar la vida entera por el sexo..." (Ibíd). A punto tal que consideramos que "[e]l sexo vale 
bien la muerte" (Ibíd). Es que “...mientras que el dispositivo de sexualidad permita a las técnicas de poder envestir la vida, el punto ficticio del sexo, que él mismo ha marcado, ejerce tanta fascinación sobre cada uno como para que se acepte escuchar allí atronar la muerte" ( Ibíd.).

En otro orden de cosas, ya en 1979, Foucault advertía el costo que tendría a futuro la disociación propiciada por el neoliberalismo entre la necesidad de expansión económica y la inversión social en la medida en que implicaba el fin de la solidaridad y de la justicia social. De esta disociación deviene una serie de prácticas que hieren de muerte a la vida desde distintos ángulos.

Tan elocuente para dar cuenta del valor de la vida, la categoría de capital humano se aplica también para desestimar las inversiones de las que no se puede obtener un rédito seguro. De allí que los seguros médicos pretendan dejar desamparados a los que nacen con ciertas deficiencias o restrinjan su cobertura a determinadas prestaciones. Los grandes laboratorios orientan sus inversiones hacia la investigación y producción, no de las drogas más necesarias sino de las más rentables. Ante la crisis, ciertos hospitales americanos han optado por sostener los servicios más prósperos.

La categoría de 'homo economicus' presta el mismo servicio a nivel laboral. A través de ella, se ha pretendido transferir al trabajador la entera responsabilidad de su devenir laboral. Según esta lógica, no es que no haya los suficientes puestos de trabajo, es que los hombres no son suficientemente emprendedores como para gestionar su vida económica y, por ende, no son merecedores de ser sostenidos en el sistema. Excluirlos del mismo es, en cierta forma, dejarlos morir. Foucault no ignoraba estas prácticas. De hecho, las abordó en su curso sobre el nacimiento de la biopolítica dictado hace ya casi cuarenta años.

\section{Conclusión}

Y a pesar del tiempo transcurrido sus análisis siguen teniendo plena vigencia.

¿Cómo acusarlo entonces de ceguera porque no abordó el tratamiento conjunto de la biopolítica y del poder soberano? ¿Cómo creer que por descuido no centró su investigación en los campos de concentración? ¿Cómo pretender que por desinterés en los problemas de la vida y la muerte se abocó al estudio de la gubernamentalidad neoliberal o que al carecer de un paradigma dúctil no pudo explicar las tendencias tanáticas del dispositivo? Cuando, en rigor de verdad, el mérito y la actualidad de su enfoque residen, por el contrario, en no haber ensayado ninguna de esas opciones. En efecto, al disociar el tratamiento de la biopolítica del ejercicio soberano del poder, logró explicitar la especificidad de un dispositivo en el que el derecho ha cedido paso a la economía y a la biología y, por ende, la ley ha sido desplazada por la norma, las medidas y las regulaciones. Al establecer su correspondencia con la aparición de la población como problema político, circunscribió las circunstancias y el periodo de su conformación a una modernidad que llega hasta nuestros días. Como llega hasta nuestros días el marco de racionalidad política en el que está inscripto. De allí que la indagación 
de la gubernamentalidad liberal y neoliberal no pueda ser vista como un desvío sino como un capítulo de las investigaciones sobre biopolítica. Y un capítulo esencial, por cuanto no solo permite identificar las tecnologías de que se vale el dispositivo para 'hacer vivir' sino también advertir cuán inherente le es 'dejar morir' y con qué empeño se aplica a cumplir su cometido.

\section{Referencias bibliográficas}

Agamben, Giorgio (2003), Homo Sacer. El poder soberano y la nuda vida. Valencia: Pre-textos.

Durkheim, Émile (2012), El suicidio. Estudio de sociología. Buenos Aires: Miño y Dávila.

Esposito, Roberto (2006), Bíos. Biopolítica y filosofia. Buenos Aires: Amorrortu.

Fassin Didier (2010), “Otra política de la vida es posible: crítica antropológica del biopoder", en Lemm, Vanessa, Michel Foucault: neoliberalismo y biopolitica, Santiago de Chile: Ediciones Universidad Diego Portales.

Foucault, Michel (1976), Histoire de la sexualité 1. La volonté de savoir. Paris: Gallimard.

(1997), "Il faut défendre la société". Cours au Collège de France 1976. Paris: Gallimard.

(2004), "Sécurité, Territoire, Population". Cours au Collège de France 1977-1978, Paris: Gallimard.

(2004a), "Naissance de la biopolitique". Cours au Collège de France 1978-1979, Paris: Gallimard.

Paltrinieri, Luca (2013), “Quantifier la qualité. Le ‘capital humaine’ entre économie, démographie et éducation”, Raisons Politiques. Revue de théorie Politique 52: 89-108. 